九州大学学術情報リポジトリ

Kyushu University Institutional Repository

\title{
Growth behavior of hydrogen micropores in aluminum alloys during high-temperature exposure
}

Toda, Hiroyuki

Department of Production Systems Engineering, Toyohashi University of Technology

Hidaka, Tatsumasa

Department of Production Systems Engineering, Toyohashi University of Technology

Kobayashi, Masakazu

Department of Production Systems Engineering, Toyohashi University of Technology

Uesugi, kentaro

Japan Synchrotron Radiation Research Institute(JASRI)

他

http://hdl. handle. net/2324/1813034

出版情報 : Acta Materialia. 57 (7)，pp.2277-2290，2009-04-01. Elsevier バージョン：

権利関係 : 


\title{
Growth behavior of hydrogen micropores in aluminum alloys during
}

\section{high-temperature exposure}

\author{
H. Toda ${ }^{\text {a }}$, T. Hidaka ${ }^{a}$, M. Kobayashi ${ }^{\text {a }}$, K. Uesugi $^{\text {b }}$, A. Takeuchi ${ }^{\text {b }}$ and K. Horikawa ${ }^{\text {c }}$ \\ ${ }^{a}$ Department of Production Systems Engineering, Toyohashi University of Technology, Toyohashi, \\ Aichi 441-8580, Japan (e-mail: toda@ pse.tut.ac.jp, tel: +81-532446697, fax: +81-532446690 (H. \\ Toda) \\ b Japan Synchrotron Radiation Research Institute, Mikazuki-cho, Sayo-gun, Hyogo 679-5198, Japan \\ ${ }^{\mathrm{c}}$ Department of Mechanical Science and Bioengineering, Graduate School of Engineering Science, \\ Osaka University, Toyonaka, Osaka 560-8531, Japan
}

\begin{abstract}
X-ray microtomography was used to observe hydrogen micropores and their growth behavior at high temperatures in several aluminum alloys. High-density micropores were observed in highpurity Al-Mg alloys, but their density and volume fraction were much lower in pure aluminum. Our results have revealed that the growth behavior of micropores is dominated by Ostwald ripening. About $53 \%$ of hydrogen is trapped in micropores in $\mathrm{Al}-\mathrm{Mg}$ alloy with low hydrogen content, making micropores the predominant hydrogen trap site. Although total hydrogen content is similar to that in the alloy, the ratio of hydrogen trapped in micropores is below $7 \%$ in pure aluminum. This difference is attributable to the lack of hydrogen precipitation sites in pure aluminium. Although the overall amounts of hydrogen at dislocations and grain boundaries are small in all the materials, the occupancies for these trap sites were concluded to be very high.
\end{abstract}


Keywords: aluminum alloys; synchrotron radiation; microtomography; hydrogen; micropore

\section{Introduction and background}

The solubility of hydrogen in aluminum is extremely small, at only $10^{-6}$ atomic fraction near the melting point, and decreases rapidly with temperature [1]. Hydrogen content extrapolated from the high temperature side is $3.9 \times 10^{-4} \mathrm{~cm}^{3}$ at room temperature, equivalent to the volume of hydrogen gas at $0{ }^{\circ} \mathrm{C}$ and $1 \mathrm{~atm}$ per $100 \mathrm{~g}$ of aluminum [1]. Measured hydrogen content ranges, however, from about $0.11 \sim 0.60 \mathrm{~cm}^{3} / 100 \mathrm{~g} \mathrm{Al}$ in wrought aluminum alloys [2] and $0.21 \sim$ several $\mathrm{cm}^{3} / 100 \mathrm{~g} \mathrm{Al}$ for cast aluminum alloys [2, 3]. These are three to four orders of magnitude larger than the above hydrogen solubility. [2]. These values may be attributable to the well-known hydrogen solubility gap at the melting temperature of aluminum [4], as a result of which solid aluminum contains supersaturated hydrogen just after solidification.

Supersaturated hydrogen must be partitioned between interstitial solution and trap sites. Hydrogen trap sites in high-purity aluminum include lattice interstices, dislocations and vacancies [5]. In the case of aluminum alloys, solute atoms, Guinier-Preston zones and subsequent metastable and stable precipitates, and high-angle grain boundaries also behave as trap sites [5, 6]. It has been claimed that there is no evidence to suggest that subgrain boundaries trap hydrogen, due to its lowenergy dislocation structure [6]. It is interesting to note that trapped hydrogen is not readily lost during storage at room temperature, or even after a combination of high-temperature exposure and hot working in the case of wrought aluminum alloys. It has been reported that the thin but robust oxide film at the surface plays an important role in impeding the release of hydrogen from solid aluminum [1]. Russell has reported that a thermally-formed oxide film drastically reduces the permeability of aluminum membranes to hydrogen [7]. The above-mentioned extraordinary hydrogen content in solid aluminum can therefore be attributed to such hydrogen occlusion due to the presence of a surface oxide layer, plus the contributions of various trap sites. 
Porosity is commonly observed in both wrought and cast aluminum alloys $[1,2,10,8]$. The porosity formation mechanisms are the precipitation of hydrogen gas or volumetric shrinkage upon solidification. Porosity can therefore be characterized as another hydrogen trap site in aluminum alloys. It has been reported, using a small-angle X-ray scattering technique, that hydrogen-vacancy defects form platelets $15 \mathrm{~nm}$ in radius and $7 \mathrm{~nm}$ in thickness lying on specific crystallographic planes [9]. This may be the direct formation mechanism of micropores in aluminum. On the other hand, Anyalebechi et al. have categorized the nucleation of micropores into several mechanisms [10], claiming that dislocation loops, formed from clustered vacancies, provide energetically favorable sites for the nucleation of hydrogen micropores as well as oxide inclusions and coarse constituent phase particles.

Ichimura et al. have investigated the effects of micropores on hydrogen diffusivity and solubility, concluding that the decrease in hydrogen diffusivity and the increase in solubility are attributable to the presence of molecular hydrogen in pores [11]. Other researchers have examined hydrogen concentration in pure aluminum, drawing the conclusion that a large amount of hydrogen is trapped in vacancy clusters or pores on a microscopic scale [12]. Thermal desorption spectroscopy (TDS) was employed by Outlaw et al. [8]. Although their technique does not provide a direct measurement of the hydrogen trapped within each pore, they have claimed that in pure aluminum, more than $99 \%$ of hydrogen is trapped in micropores. Percentage porosity has, in fact, been closely studied, and proves to depend on the hydrogen content in aluminum alloy $[1,13,14]$, strongly suggesting that micropores in aluminum alloys are filled and pressurized with molecular hydrogen. Another point to note is that high-purity aluminum usually shows much lower porosity for a given hydrogen content [14]. It can be inferred that this difference is associated with the kinds and density of available trap sites in high-purity aluminum. It will be examined fully later in the present experiment.

The mechanical properties of aluminum alloys are sometimes sensitive to the presence of micropores [14]. In response to this, the relationship between metal working and micropore healing 
has been well documented $[1,14,15]$. Wang et al. have reported the necessary hydrostatic pressure and holding time to realize the healing of micropores. On the other hand, it has been claimed that interdendritic porosity in cast aluminum alloys does not close completely in the course of metal working. Instead, it is flattened, thereby reducing its short-transverse mechanical properties [1]. This so-called secondary porosity has been reported to remain unchanged through extensive deformation by hot and cold rolling [1]. Direct observation of healing/reopening during plastic working and subsequent heat treatments will be undertaken in another paper [16].

Numerous experimental reports are available in the literature that report micropore growth at high temperatures $[3,10,17,18]$. However, in the conventional cross-sectional or surface observations, micropores are easily filled with abrasive powders during sample preparation processes for the observations, such as cutting and polishing [19,20,21,22,23], resulting in uncertainty and inaccuracy in micropore observation. In the present study, synchrotron X-ray microtomography with recently enhanced resolution levels [24] was applied to clarify the above issues. Also, the high resolution 3-D/4-D (i.e., 3-D plus time axis) imaging readily enables the visualization of individual microstructural features, providing a unique opportunity to quantitatively analyze the growth, shrinkage and annihilation behavior of each pore. This is clearly an improvement on the procedures applied in the available literature, which allow only macroscopic evaluations.

\section{Experimental methods}

\subsection{Sample preparation}

Aluminum of $99.999 \%$ purity (Sumitomo Chemical Co., Ltd.) and pure magnesium were used to prepare Al-5.5 mol\% Mg alloys. The purity of the magnesium was $99.97 \%$ (Ube Co., Ltd.) and $99.98 \%$ (Timminco Co., Ltd.) for alloys $\mathrm{MH} / \mathrm{HH}$ (as hereinafter described) and alloy LH (as 
hereinafter described), respectively. Crucibles for the former and latter alloys were made of alumina at $99 \%$ purity (TEP Co., Ltd.) and for electrode-grade graphite (Shin-Nihon Tanso Co., Ltd.), respectively. The Al-5.5 mol\% Mg binary alloy was melted in an atmosphere of argon and cast into iron molds (for simplicity, mol\% is expressed as \% below). Here, a melting atmosphere of argon was applied to avoid hydrogen contamination. This alloy is hereinafter called alloy LH to indicate its low hydrogen content. Another $\mathrm{Al}-5.5 \% \mathrm{Mg}$ alloy, melted in ambient laboratory air, is hereinafter called alloy $\mathrm{MH}$. The details of the chemical compositions of alloy LH and MH are available elsewhere [25] (Alloys LH and MH correspond to Alloy-3 and Alloy-4, respectively, in the reference paper.). These ingots were homogenized at $703 \mathrm{~K}$ for $18 \mathrm{~h}$ in an argon atmosphere. A part of the alloy $\mathrm{MH}$ ingot was remelted in ambient laboratory air. Before remelting, $\mathrm{TiH}_{2}$ was added to a crucible with a cover to raise the hydrogen partial pressure during melting. $\mathrm{TiH}_{2}$ decomposes below the melting point of the aluminum alloy. The alloy melt was protected from contamination with any remaining $\mathrm{Ti}$ by placing an appropriate divider plate in between. The material is hereinafter called alloy $\mathrm{HH}$. All the $\mathrm{Al}-5.5 \mathrm{~mol} \% \mathrm{Mg}$ alloys contained impurity silicon of $0.003 \sim 0.004$ mass \%. No other impurity such as Fe, $\mathrm{Na}$ and $\mathrm{Ca}$ was detected. Aluminum at 99.999\% purity, hereinafter called $5 \mathrm{~N}-\mathrm{Al}$, was also used for comparison purposes. To avoid contamination, no homogenization treatment was applied to $5 \mathrm{~N}-\mathrm{Al}$.

The three Al-Mg alloys were then exposed at $823 \mathrm{~K}$ for 0 to $270 \mathrm{~h}$ to observe any changes in micropore morphology. Changes during the homogenization treatment at $703 \mathrm{~K}$ for $18 \mathrm{~h}$ were also observed only for alloy $\mathrm{HH}$. A specimen $15 \mathrm{~mm}$ in length and 0.6 x $0.6 \mathrm{~mm}$ in cross section and one $7 \mathrm{~mm}$ in length and $0.05 \times 0.05 \mathrm{~mm}$ in cross section were machined from the ingots and used for projection-type and imaging-type microtomography observations, respectively.

The vacuum fusion method was utilized to measure the total hydrogen content of each material. Dislocation density was measured using Keh's method [26] on $\{100\}$ faces observed with a transmission electron microscope operated at $200 \mathrm{kV}$. Grain size was measured using an optical microscope after etching polished samples by means of Barker's method. 


\subsection{Tomographic imaging}

X-ray tomography was performed at the undulator beamline BL47XU of the SPring-8 synchrotron radiation facility. A monochromatic X-ray beam with a photon energy of $20 \mathrm{keV}$, produced by a liquid nitrogen-cooled Si (111) double crystal monochromator, was used for the projection-type microtomography. A beam diffuser rotating at $600 \mathrm{rpm}$, packed with graphite powder, was employed to modify the high coherence of the X-rays. An image detector was positioned $20 \mathrm{~mm}$ behind the sample, making the imaging system sensitive to phase modulation in addition to the classical absorption contrast [27]. The image detector consisted of a cooled $4000(\mathrm{H})$ x 2624 (V) element CCD camera (effective pixel size of the camera: $5.9 \mu \mathrm{m}$ ), which was used in $2 \mathrm{x}$ 2 binning mode, a scintillator $\left(\mathrm{Lu}_{2} \mathrm{SiO}_{5}: \mathrm{Ce}\right)$ and a relay lens $(\times 20)$. In total, 1500 radiographs, scanning 180 degrees, were obtained in 0.12-degree increments. The entire cross-section of the specimen and a region about $622 \mu \mathrm{m}$ high were captured on the CCD camera.

Imaging-type microtomography, which has state-of-the-art high resolution, was performed at 8 $\mathrm{keV}$. A schematic illustration of the setup is available elsewhere [28]. The system consists of the beam diffuser, high precision stages, a center beam stop, a condenser zone plate (CZP), a pinhole as an order- sorting aperture for the CZP, a Fresnel zone plate (FZP) and the X-ray image detector. The accuracy of the sample rotary stage, which is one of the key issues in determining the whole resolution of the imaging $\mathrm{CT}$, showed less than $\pm 70 \mathrm{~nm}$ wobble during $360^{\circ}$ rotation [28]. The CZP has a concentric grating pattern with an even zone width, and was utilized as an illumination device for Köhler's illumination under a quasi-parallel beam from the synchrotron radiation. First-order diffraction was used for illumination purposes. The FZP was used as an objective. The focused beam size of the 1st-order diffraction of the FZP was measured as $120 \mathrm{~nm}$ in full width at half maximum, almost equal to the diffraction-limited spot size defined by Rayleigh's criterion. Both CZP and FZP were fabricated using an electron-beam lithography technique. The detector consisted of a thin phosphor $\left(\mathrm{P} 43, \mathrm{Gd}_{2} \mathrm{O}_{2} \mathrm{~S}: \mathrm{Tb}+\right)$ screen, tandem camera lens and the cooled CCD camera (as 
above). The CCD camera was also used in the $2 \times 2$ binning mode. The exposure time for each projection was $500 \mathrm{msec}$ (at $8 \mathrm{keV}$ ). Total scan time for 1,500 projections was about 30 minutes.

\subsection{3-D image reconstruction and subsequent image analysis}

Image slices were reconstructed from a series of projections based on the conventional filtered backprojection algorithm. The grey value in each dataset was calibrated such that the linear absorption coefficient of $0 \sim 20 \mathrm{~cm}^{-1}$ fell within an 8-bit grayscale range between 0 and 255 . Isotropic voxels with 0.474 and $0.088-\mu \mathrm{m}$ edges were achieved in the reconstructed slices for the projection- and imaging-type setups, respectively.

To estimate the volume of each micropore at sub-voxel accuracy, pentagonal facetted isointensity surfaces were computed from the volumetric data set using the conventional Marching Cubes algorithm [29]. A threshold value to obtain binary images was chosen as a median between the linear absorption coefficient peaks of air and the aluminum matrix. To suppress inaccuracies originating from image noise, only micropores over 6.668 voxels in volume were counted as micropores in the quantitative analysis.

Figure 1 (a) illustrates a two-dimensional (2-D) grey value distribution on a virtual slice where three micropores and some particles, which are seen in black and white respectively, are embedded in a grey aluminum matrix. In general, light and dark fringes appear at each micropore/matrix and particle/matrix interfaces due to Fresnel diffraction [30]. A pair of light and dark fringes must also appear at a particle/micropore interface if there is such an interface in the materials used. The existence of such an interface implies that pre-existing particles act as heterogeneous nucleation sites. Due to the existence of such fringes, however, it is hard to confirm if micropores are attached directly to particles or there is intervening matrix aluminum in between, as seen in Fig. 1 (b), which is the result of segmenting the virtual cross-sectional image shown in Fig. 1 (a). For closer examination, segmented micropores were expanded in 3-D, as shown in Fig. 1 (c). The ratio of micropores nucleated heterogeneously on particles was estimated by changing the degree of 
expansion.

\section{Micropore growth behavior at high temperatures}

\subsection{Observation with projection-type setup}

Figure 2 shows the 3-D reconstructed images of micropores in as-cast, homogenized and heattreated conditions in alloy $\mathrm{HH}$. Note that only micropores are extracted, while underlying aluminum and dispersion particles are not displayed in Figure 2. In the as-cast condition, interdendritic shrinkage cavities with complex shapes are seen together with small, high-density micropores. During the homogenization treatment at $703 \mathrm{~K}$ for $18 \mathrm{~h}$ and subsequent high temperature exposure at $823 \mathrm{~K}$ for $90 \mathrm{~h}$, the shrinkage cavities gradually shrank and spheroidized as is indicated in circle A. Instead, small and high-density micropores were grown, making overall spatial distribution relatively homogeneous, as seen in Fig. 2 (c). Such growth might be attributable to the creep deformation of aluminum around the micropores due to the presence of high hydrogen pressure in the micropores.

Similar observations for alloys $\mathrm{MH}$ and $\mathrm{LH}$ and $5 \mathrm{~N}-\mathrm{Al}$ are shown in Figs. 3 - 5. It appears that although, as is shown later, the hydrogen content of the two alloys is similar according to the macroscopic hydrogen analysis, alloy $\mathrm{MH}$ is thought to contain more significant shrinkage cavities than alloy HH. On the other hand, alloy LH exhibits much fewer shrinkage cavities than alloys MH and $\mathrm{HH}$. It is interesting to note that micropores in alloys $\mathrm{LH}$ and $\mathrm{MH}$ show angular shapes after being exposed to $823 \mathrm{~K}$ for $90 \mathrm{~h}$. Micropores in alloy $\mathrm{HH}$ also exhibited slightly angular shapes after exposure for $270 \mathrm{~h}$. A closer inspection revealed that the angular micropores exhibit octahedral shape with some type of crystallographic orientation relationship with the underlying aluminum matrix. It can be inferred that if hydrogen trapped in micropores is released from the alloys, micropores with lower internal gas pressure reach an equilibrium between internal gas pressure and surface energy, and change their shape to reduce the surface energy. Since the $\{111\}$ planes have the 
lowest surface energy of all the low-index planes in aluminum [31], it is reasonable to assume that micropores are prone to form octahedra surrounded by eight $\{111\}$ planes, making them energetically stable in aluminum. Similar faceted pores have been observed in a $\mathrm{Nb}-\mathrm{Zr}$ alloy implanted with He, which exhibited 18-sided polyhedral pores bounded by (100) and (110) faces [32]. The alignment of the angular micropores over a relatively large volume is attributable to the very large grain size of the Al-Mg alloy used (typically $100 \sim 400 \mu \mathrm{m}$ ). There is a marked difference in the appearance of the micropore distribution in $5 \mathrm{~N}-\mathrm{Al}$ compared to the $\mathrm{Al}-\mathrm{Mg}$ alloys. Only two ellipsoidal and coarse micropores were observed in $5 \mathrm{~N}-\mathrm{Al}$, and their appearance did not significantly change, even after exposure to $823 \mathrm{~K}$ for $90 \mathrm{~h}$, as shown in Figure 5.

Figure 6 shows magnified views of micropore distributions for alloy $\mathrm{MH}$ and $5 \mathrm{~N}-\mathrm{Al}$. A variety of behaviors, such as the growth, coalescence, shrinkage and annihilation of the micropores, are demonstrated in this tiny volume. For example, pore A was annihilated after $10 \mathrm{~h}$ of heat treatment. Pore B grew up to $30 \mathrm{~h}$ and then coalesced with a neighboring pore. Pore $\mathrm{C}$ also appeared to grow up to $30 \mathrm{~h}$ and then self-annihilated. Meanwhile, pore D showed monotonic growth up to $90 \mathrm{~h}$. Fundamentally, micropores can grow by two different mechanisms: one is Ostwald ripening and the other is migration and coalescence. The former mechanism needs gas re-solution and the latter is likely to occur as a result of gas surface diffusion and/or vacancy volume diffusion. Detailed inspection of the tomographic volumes in this study did not reveal any migration of micropores. A more quantitative discussion on this issue will appear later. Although it is not seen in Figure 6, newly-initiated small spherical micropores were also seen in other regions. One coarse micropore and another very small micropore beside it are seen in Figure 6 (b). Both of these micropores showed very gradual shrinkage behavior during the period of $90 \mathrm{~h}$, but it might be conceivable only after $90 \mathrm{~h}$ has elapsed. The change in the shape of micropores from spheroid to octahedral is also clearly confirmed in Figure 6. 
Figure 7 shows a high-resolution 3-D image of material $\mathrm{HH}$ that has been captured after homogenization treatment at $703 \mathrm{~K}$ for $18 \mathrm{~h}$. In this figure, a translucent image of the specimen shown in grey has been superposed on the micropore image shown in red. It can be confirmed that there are no micropores smaller than $1 \mu \mathrm{m}$. Since the resolution of the projection-type microtomography such as used for Figs. $2-6$ is approximately $1 \mu \mathrm{m}$, it can be concluded that all the micropores embedded in the materials used can be observed using projection-type microtomography. Subsequent quantitative analysis will therefore be performed solely on the basis of the microtomography images taken using the projection-type setup.

\subsection{Results of 3-D quantitative analysis}

Figures $8 \sim 10$ show the results of the 3-D quantitative analysis. The number density of the micropores was $16.1,50.7$ and $54.7 \times 10^{12} \mathrm{~m}^{-3}$ for alloys $\mathrm{LH}, \mathrm{MH}$ and $\mathrm{HH}$, respectively. The number densities markedly decrease with exposure at $823 \mathrm{~K}$ in the cases of alloys $\mathrm{LH}$ and $\mathrm{HH}$, while alloy $\mathrm{MH}$ showed a rapid increase up to $30 \mathrm{~h}$ and then began to decrease. The number density of micropores for $5 \mathrm{~N}-\mathrm{Al}$ remained at less than one-tenth of those of the $\mathrm{Al}-\mathrm{Mg}$ alloys throughout the high-temperature exposure. It seems to be consistent with the past literature that high-purity aluminum shows much lower porosity for a given hydrogen level [14]. Indeed, the reported difference in volume fraction between $99.99 \%$ aluminum and aluminum alloys, such as $99.2 \%$ aluminum and $\mathrm{Al}-4.6 \% \mathrm{Cu}$ alloy, for hydrogen content of $0.3 \mathrm{~cm}^{3} / 100 \mathrm{~g} \mathrm{Al}$ is $8 \sim 10$ times, which is even larger than the difference between alloy $\mathrm{LH}$ and $5 \mathrm{~N}-\mathrm{Al}\left(0.29 \sim 0.3 \mathrm{~cm}^{3} / 100 \mathrm{~g} \mathrm{Al}\right)$ shown in Fig.10 [14]. Average micropore diameter increased rapidly in the cases of alloys LH and HH, whereas it was almost flat in alloy $\mathrm{MH}$ and $5 \mathrm{~N}-\mathrm{Al}$, as shown in Figure 8. In alloys $\mathrm{LH}$ and $\mathrm{HH}$, the size distributions changed from a narrow distribution, centered at about $3 \mu \mathrm{m}$ with similar diameter to the as-homogenized condition, to a broad distribution peaking at $8 \sim 13 \mu \mathrm{m}$ after exposure at 823 $\mathrm{K}$ for 90 h, as shown in Figure 9.

These patterns of number density and size distribution suggest that the micropore growth 
behaviors in alloys $\mathrm{LH}$ and $\mathrm{HH}$ are dominated by Ostwald ripening. In alloy $\mathrm{HH}$, the average diameter began to decrease again at the longest time period, as seen in Figure 8. This suggests the possibility of a decrease in hydrogen content during long exposure. Alloy MH 9 (Figure 9) showed a relatively irregular size distribution. The singular behavior in size and number density observed in alloy MH might be attributable to its characteristic pore distribution: an enormous shrinkage cavity, several hundred micrometers across, as seen in Fig. 3, which almost reaches the length of a diagonal line for the tomographic region of interest. The volume fraction of micropores shown in Fig. 10 increased rapidly after $5 \mathrm{~h}$ had elapsed at $823 \mathrm{~K}$ in all the $\mathrm{Al}-\mathrm{Mg}$ alloys. This time period is close to the standard solution treatment time for aluminum alloys. Meanwhile, volume fraction decreased monotonically in $5 \mathrm{~N}-\mathrm{Al}$, in marked contrast to the Al-Mg alloys. These results indicate that the prolongation or repetition of heat treatment might inevitably cause a degradation in mechanical properties due to the growth of micropores. It seems most likely that micropores can be healed during cold and/or hot plastic working before being exposed at the solution treatment temperature. Complementary studies on this will be available in a companion paper [16].

\section{Discussion}

\subsection{Nucleation sites for micropores}

Figure 11 shows variation in the ratio of micropores directly attached to particles, $P_{\mathrm{h}}$, after each micropore has been dilated at one-voxel intervals. If micropores and particles both independently nucleate and no preferential sites are available for them, the distance between a micropore and the nearest particle would tend to be randomly distributed. In this case, $P_{\mathrm{h}}$ would be expected to increase moderately with the dilation width, $w_{\mathrm{d}}$. However, if there are micropores heterogeneously nucleated on particles, the presence of light and dark fringes in between, caused by the Fresnel diffraction, might cause an apparent separation between particles and micropores. In this case, $P_{\mathrm{h}}$ is expected to increase rapidly until $w_{\mathrm{d}}$ reaches the width of the light and dark fringes and then 
decelerate rapidly to a more moderate rate of increase, dominated by statistical encounters with neighboring particles. Figure 11 illustrates this tendency, suggesting the presence of heterogeneously nucleated micropores. The intersection point of two auxiliary lines in Fig. 11 gives $P_{\mathrm{h}}$ of $59.6 \%$ at a $w_{\mathrm{d}}$ of about $2.0 \mu \mathrm{m}$ (i.e., four voxels).

The first Fresnel zone size is given as $(\lambda d)^{0.5}$, where $\lambda$ is the wavelength of the X-rays and $d$ is the sample/detector distance [33]. $\lambda=0.062 \mathrm{~nm}$ and $d=20 \mathrm{~mm}$ in this study, resulting in a $(\lambda d)^{0.5}$ value of $1.1 \mu \mathrm{m}$. Since a pair of light and dark fringes is seen in the tomographic images, it would be reasonable to take the second Fresnel zone size, which is almost equivalent to the obtained $w_{\mathrm{d}}$ value. It can therefore be concluded that the majority of the micropores have been nucleated on preexisting particles. Since the resolution level for current projection-type tomography is about $1 \mu \mathrm{m}$, there would appear to be a large number of sub-micron particles in the materials used that are not visible using the current projection-type setup. The obtained $P_{\mathrm{h}}$ value of $59.6 \%$ would therefore be more or less an underestimated value, and the actual ratio would be much higher.

As was described in the Introduction, it has been reported that nanometer-sized platelets form from hydrogen-vacancy defects [9] and that dislocation loops form from clusters of vacancies [10], providing energetically favorable sites for the nucleation of hydrogen micropores. This means that the formation mechanism of micropores is homogeneous nucleation. According to the present analysis, however, at least $60 \%$ of micropores have been formed heterogeneously on constituent particles. There is little evidence within the present study that vacancies are involved in the formation process of micropores in any form. As is shown in Table 3, total hydrogen content is almost identical between alloy LH and $5 \mathrm{~N}-\mathrm{Al}$. Nevertheless, the present study reveals a marked difference between them in the number density and size of micropores. It might also support the above hypothesis that micropores are formed heterogeneously on particles. In other words, heterogeneous nucleation sites appear to be necessary for hydrogen to form micropores, and if not, micropore formation is effectively suppressed. This will be analyzed later where hydrogen, which has failed to form micropores, is trapped in pure aluminum. 


\subsection{Micropore growth mechanism}

It would be reasonable to assume that the observed micropores have been in thermal equilibrium where surface tension, $\gamma$, is balanced by an opposing gas pressure inside a micropore, $P$, as follows:

$$
4 \gamma / d=P
$$

where $d$ is the micropore radius [34]. Two possible growth mechanisms under such thermal equilibrium would be micropore migration/coalescence and Ostwald ripening [35]. For the former mechanism to operate, micropores should migrate via atom transport through surface diffusion, vacancy volume diffusion or vapor transport through gas [35]. According to Nichols [36], mean micropore diameter, $\bar{d}$, and number density, $\rho_{\mathrm{p}}$, are expressed as follows if ideal gas behavior and spherical micropores are assumed:

$$
\begin{gathered}
\bar{d} \propto\left(D M_{H} t\right)^{1 / n} \\
\rho_{P} \propto C_{H}\left(D M_{H} t\right)^{-2 / n}
\end{gathered}
$$

where $\mathrm{D}$ is the diffusion coefficient of aluminium, $M_{\mathrm{H}}$ is total hydrogen content and $t$ is time. On the other hand, according to the model for Ostwald ripening proposed by Greenwood et al. [37], $\bar{d}$ and $\rho_{\mathrm{p}}$ are expressed based on the same assumptions as Eqs. (2) and (3), as follows:

$$
\begin{gathered}
\bar{d} \propto\left(D_{H} C_{H} t\right)^{1 / 2} \\
\rho_{P} \propto M_{H}\left(D_{H} C_{H} t\right)^{-1}
\end{gathered}
$$


where $D_{\mathrm{H}}$ is the diffusion coefficient of hydrogen in aluminium and $C_{\mathrm{H}}$ is the hydrogen concentration in the aluminum matrix. Eqs. (2) - (5) indicate that in the case of migration- and coalescence-dominated growth, both $\bar{d}$ and $\rho_{\mathrm{p}}$ are functions of $M_{\mathrm{H}}$. Meanwhile, if Ostwald ripening dominates, only $\rho_{\mathrm{p}}$ is a function of $M_{\mathrm{H}}$, and $\bar{d}$ is independent of $M_{\mathrm{H}}$.

Table 1 shows $\bar{d}, \rho_{\mathrm{p}}$ and $M_{\mathrm{H}}$ for the three Al-Mg alloys in the as-homogenized condition. The reason that only the as-homogenized condition is provided for the analysis is that a decrease in $M_{\mathrm{H}}$ might be expected during long exposure at $823 \mathrm{~K}$, as was suggested in Figure 8 . It can be seen in Table 1 that $\bar{d}$ is nearly constant, while $\rho_{\mathrm{p}}$ shows some dependency on $M_{\mathrm{H}}$, suggesting that Ostwald ripening is predominant in the growth behavior of micropores in the present materials. As indicated in Eq. (5), $\rho_{\mathrm{p}}$ is not linearly proportional to $M_{\mathrm{H}}$. This is likely due to the limited size range of micropores provided for in the quantitative analysis.

Markworth et al. have also analyzed the asymptotic coarsening kinetics in the case of Ostwald ripening and shown asymptotic size distribution functions [38]. According to their analysis, the maximum micropore diameter, $d_{\max }$ is expressed as follows.

$$
d_{\max } \approx 2.36 \bar{d}
$$

Table 2 shows the $d_{\max } / \bar{d}$ ratio calculated using the tomographic data. The values just after the homogenization treatment range from 2.2 to 2.3 , averaging 2.23. A similar tendency has been confirmed by the present authors for a commercial wrought aluminium alloy [39]. Agreement with Markworth's analysis also supports the predominance of Ostwald ripening, which is also in qualitative agreement with the observations shown in Figs. $2-6$.

\subsection{Hydrogen trapped within micropores}

Hydrogen gas trapped within micropores might be amenable to measurement using 
conventional analytical methods such as electron-energy-loss spectroscopy (EELS) and ultraviolet absorption spectroscopy (UVAS) as energy shifts of hydrogen excitations [40]. Huang diffuse scattering (HDS) has also been applied to visualize strain fields around pores [40]. However, there are certain size ranges for which these techniques are suited. For examples, EELS and UVAS cover $1 \sim 100 \mathrm{~nm}$, while HDS can be applied to micropores smaller than $10 \mathrm{~nm}$ [40]. Therefore, micropores observed in the present study cannot be measured with these techniques. In addition, these techniques provide only macroscopically averaged information, and hydrogen trapped in individual micropores is out of reach of measurement.

It has been reported for very small pores $(d<100 \mathrm{~nm})$ that equilibrium pressure and gas density can no longer be described by the ideal gas law [35]. However, this is not the case: all the micropores observed in the present study can be analyzed with reasonable accuracy using the ideal gas law. Above $T_{\mathrm{m}} / 2$ ( $T_{\mathrm{m}}$ : melting temperature), thermal vacancy absorption is rapid enough to maintain the gas pressure within micropores at the equilibrium value characterized in Eq. (1) [40]. This is because the equilibrium concentration of vacancies is approximately three orders of magnitude higher than the solubility of hydrogen at the melting point of aluminium [41]. By combining Eq. (1) with the ideal gas law, hydrogen trapped in all the micropores, $C_{\text {pore }}(\mathrm{mol})$, is given by summing the hydrogen content in every micropore as follows:

$$
C_{\text {pore }}=\Sigma\left(\frac{2 \pi \gamma d_{i}^{2}}{3 R T}\right)
$$

where $d_{i}$ is the diameter of the $i$ th micropore, $\mathrm{R}$ is the gas constant and $T$ is temperature. $\gamma$ was assumed to be $1.16 \mathrm{~N} / \mathrm{m}$, which is the measured value for the (111) face [42]. Since the (111) face has the minimum energy in aluminum, the calculation yields conservative lower limit values. The diameter of each micropore is known from the tomographic data, so $C_{\text {pore }}$ can therefore be readily obtained, as shown in Table 3. Here, the total hydrogen trapped is expressed as the equivalent 
volume of hydrogen gas at $0{ }^{\circ} \mathrm{C}$ and $1 \mathrm{~atm}$ per $100 \mathrm{~g}$ of aluminum, $M_{\mathrm{H}}{ }^{\text {pore }}$. It's important to note that micropores should be in thermal equilibrium as eq. (1) to obtain $C_{\text {pore }}$. Since micropores are expanded due to creep deformation of the aluminium matrix during the exposure at $823 \mathrm{~K}$ as shown in Figs. 8 and 9, the analysis has been applied only to the materials without the exposure. It is noteworthy that about $53 \%$ of hydrogen is trapped within the micropores in alloy LH, while although the total hydrogen content is similar, it is less than $7 \%$ in $5 \mathrm{~N}-\mathrm{Al}$. This difference may be attributable to the lack of hydrogen precipitation sites in the pure aluminium, as discussed above. $M_{\mathrm{H}}{ }^{\text {pore }}$ is also a low $3 \sim 9 \%$ for alloys $\mathrm{MH}$ and $\mathrm{HH}$. Since the total hydrogen in these alloys was very high, it can be inferred that the way that hydrogen is partitioned into possible trap sites would be different if the total hydrogen content is high.

As stated earlier, Outlaw et al. performed a thermal desorption experiment [8], concluding that, in pure aluminum, more than $99 \%$ of hydrogen is trapped in micropores. This is starkly inconsistent with the results obtained in this study. In their technique, a gas pulse observed before the melting of aluminum was assumed to correspond to the desorption of hydrogen from all the pores. It is not clear at this moment whether the inconsistency can be traced to their indirect measurement method or to marked difference in the state of the materials used.

\subsection{Estimation of hydrogen trapped at each trap site}

Available trap sites for hydrogen in aluminum are lattice interstices, dislocations, vacancies, solute atoms, precipitates and high-angle grain boundaries. Of these, the vacancy and precipitate can be neglected for the materials used because they are analyzed after being cooled slowly from the homogenization temperature. In $5 \mathrm{~N}-\mathrm{Al}$, grain size is a few tens of millimeters, suggesting that no grain boundaries are present in the present tiny tomographic sample. Microstructural parameters associated with the trap sites are listed for the materials used in Table 4.

Smith et al. have performed TDS experiments for hydrogen pre-charged aluminum alloys with a varying thermal ramp rate, estimating binding energies for various trap sites based on Arrhenius 
plots [43]. According to them, trap binding energy, $E_{\mathrm{b}}$, for the interstitial lattice, dislocations and high angle boundaries is $0,31.7$ and $35 \mathrm{~kJ} / \mathrm{mol}$, respectively. No hydrogen trapping at sub-grain boundaries was identified in their study. The $E_{\mathrm{b}}$ value for dislocations in $99.999 \%$ aluminum has been also reported by Young et al. to be $27.3 \mathrm{~kJ} / \mathrm{mol}$ [4], which is close to the above value. The binding energy between hydrogen and solute magnesium atoms has been measured by Leger et al. to be $E_{\mathrm{b}}<5.8 \mathrm{~kJ} / \mathrm{mol}$ in high purity Al-Mg alloys [44]. Smith et al. have analyzed trapped hydrogen in each trap site together with trap coverage with hydrogen [43]. In the following part, a similar procedure is applied to measuring hydrogen partitioning in the materials used. Hydrogen stored in normal interstitial lattices and other trap sites should, according to Oriani's theory, always be in equilibrium as follows [45]:

$$
\frac{\theta_{T}}{1-\theta_{T}}=\theta_{L} \exp \left(\frac{E_{b}}{R T}\right)
$$

where $\theta_{\mathrm{L}}$ and $\theta_{\mathrm{T}}$ denote the occupancy of the interstitial sites and trap sites, respectively. Total hydrogen concentration, measured in hydrogen atoms per unit volume, $C^{\mathrm{T}}{ }_{\mathrm{H}}$, is the sum of the hydrogen stored in a normal interstitial lattice and all the trap sites, corresponding to the total hydrogen content listed in Table 3:

$$
C_{H}^{T}=\theta_{L} N_{L}+\Sigma \theta_{T i} N_{T i}+C^{\prime}{ }_{p o r e}
$$

where $N_{\mathrm{L}}$ and $N_{\mathrm{T} i}$ (atoms per unit volume) respectively denote trap densities in the normal interstitial lattice and $i$ th trap sites other than micropores. $C$ ' ${ }_{\text {pore }}$ represents total hydrogen atoms per unit volume trapped in micropores, which can be converted from $C_{\text {pore }}$. Table 5 shows the values of the trap density estimated from the measured dislocation density, grain size and the concentration of solute magnesium. Trap site occupancy and the concentration of hydrogen for each trap site are 
listed in Table 5. In this analysis, $E_{\mathrm{b}}$ for solute magnesium was assumed to be its upper limit, i.e., $5.8 \mathrm{~kJ} / \mathrm{mol}$, and $E_{\mathrm{b}}$ values for other trap sites were taken from Smith's paper [43].

Due to the relatively low dislocation density and coarse grain size in the Al-Mg alloys used, the hydrogen trapped at these trap sites is limited. It is also worth noting that the trap site occupancy values are high for dislocations and grain boundaries, ranging from 0.357 to 0.970 and 0.677 to 0.992, respectively. The total amounts of hydrogen trapped in micropores are similar in the three Al$\mathrm{Mg}$ alloys. Since the total hydrogen content is significantly lower in alloy LH than in alloys MH and $\mathrm{HH}$, micropores are the major hydrogen trap site in alloy $\mathrm{LH}$, higher than the interstitial lattice by a factor of 2.46. In general, it is well known that apparent hydrogen diffusivity, $D_{\mathrm{a}}$, is reduced with $D_{\mathrm{a}}=D_{\mathrm{L}} /(1+\phi)[46]$, where $D_{\mathrm{L}}$ is the ideal diffusivity of hydrogen in aluminum and $\phi$ is the ratio of hydrogen between the trapped sites and interstitial lattices given by $\phi=\left(\Sigma \theta_{T i} N_{T i}+C^{\prime}{ }_{p o r e}\right) / \theta_{L} N_{L}$ from Eq. (9). The result in Table 5 indicates that $D_{\mathrm{a}}$ is reduced by about $80 \%$ in alloy LH due to the high ratio of hydrogen trapped in the microstructural defects.

Although hydrogen trapped in micropores is different by a factor of 3.4 in alloys $\mathrm{MH}$ and $\mathrm{HH}$, similar ratios (about 62\%) of the total hydrogen are located in the interstitial lattices in both alloys. This is in contrast to the common knowledge that the true interstitial lattice solubility in aluminum is relatively small compared to other solid FCC metals. It can be inferred that excess hydrogen in solid aluminum is predominantly partitioned to micropores, and the occupancies for interstitial lattices, dislocations and grain boundary sites are elevated with further increases in hydrogen concentration. The reason that more hydrogen is not held in micropores might be mutual interaction between neighboring micropores.

Comparison of alloy $\mathrm{LH}$ and $5 \mathrm{~N}-\mathrm{Al}$, which have a similar total hydrogen content, indicates that if micropores cannot precipitate on some preferential sites, dislocations store a large amount of hydrogen, bringing levels close to those of the high-hydrogen alloys $\mathrm{MH}$ and $\mathrm{HH}$. It has been reported that the formation of blisters is suppressed by applying cold deformation of $20 \sim 60 \%$ [47]. This may be consistent with the high trap site occupancies at dislocations, which are close to unity 
for alloys $\mathrm{MH}$ and $\mathrm{HH}$. Cold deformation inevitably leads to an increase in dislocation density, as a result of which the capacity for hydrogen storage at dislocations would be significantly expanded. Grain boundary-trapped hydrogen concentration has been measured and analyzed, and in the literature it is associated with hydrogen embrittlement behavior $[48,49]$. There has been a certain amount of controversy concerning grain boundary trapping, since it has sometimes been reported that hydrogen segregation is not observed experimentally [4,50]. The estimated value for grain boundary trapping has yielded the lowest value in each material, which is one to two orders of magnitude smaller than the other trap sites. It might be reasonable to suppose that even a small amount of hydrogen trapped at grain boundaries can have a strong influence on fractures, but since a grain boundary is a 2-D defect, the absolute amount of hydrogen stored at grain boundaries was confirmed to be very low in the present analysis.

\subsection{Insights into practical material manufacturing processes}

In general, high-temperature heat treatments are performed on aluminum alloys with the aim of the eliminating segregation and coarse intermetallic particles and/or solutionization. However, in the light of the findings of the present study, heat treatment conditions should be controlled such that both homogenization/solutionizing (positive effects) and the suppression of micropore growth (negative effects) are satisfied in an optimal balance from a practical point of view. For examples, a shorter heat treatment might sometimes bring a better result. The fundamental mechanism of micropore growth and the hydrogen partitioning behavior into micropores, which have been clarified in the present study, would provide valuable insights for advanced property controls of this type. Since wrought aluminum alloys experience some plastic working before usage, it is indispensable to assess the shrinkage and annihilation behaviors of micropores in subsequent metal working processes. The results of the direct observation of healing/reopening during plastic working and subsequent heat treatments performed in another paper [16] should also be taken into account to make the heat treatment control more efficient. 
It is also interesting to note that micropore formation is suppressed in the absence of alloying elements. In practical aluminum alloys with some alloying elements, the existence of numerous micropores would exert some effects on mechanical properties. For example, it has been reported that tensile strength decreases rapidly if porosity increases up to $0.5 \sim 1 \%$ [1]. The high resolution 3-D/4-D imaging also enables the visualization of individual microstructural features, providing a unique opportunity to reveal the contribution of each pore on fracture. It will be reported by the present authors in another paper [51], providing more detailed information on the microstructural control in the heat and thermo-mechanical treatments.

\section{Summary}

Synchrotron X-ray microtomography was used to observe hydrogen micropores and their shrinkage, annihilation, initiation and growth behaviors during high-temperature exposure in highpurity Al-Mg alloys with three different hydrogen contents and in $99.999 \%$ pure aluminum. Ultrahigh-resolution imaging tomography was also used to identify the minimum pore size in the materials.

High-density micropores were observed in the Al-Mg alloys, while the density and overall volume fraction of micropores were much lower in pure aluminum. At least $60 \%$ of micropores had been formed heterogeneously on constituent particles. There is little evidence within the present study that vacancies are involved in any way in the formation process of micropores. It was clarified that the growth behavior of micropores is dominated by Ostwald ripening. Hydrogen trapped in all the micropores was estimated, assuming a) that a thermal equilibrium exists between surface tension and $b$ ) that the internal gas pressure in the micropores obeys the ideal gas law. Unlike macroscopic measurements such as the thermal desorption spectroscopy, this study would be the first direct and local approach to estimate hydrogen trapped at micropores. Combining with 
some theoretical considerations on hydrogen trapping, the hydrogen trapped at the other trap site was also estimated. It is noteworthy that about $53 \%$ of hydrogen is trapped within micropores in the Al-Mg alloy with low hydrogen content, while although the total hydrogen content was similar, it was less than $7 \%$ in pure aluminum. This difference is attributable to the lack of hydrogen precipitation sites in pure aluminium. Hydrogen partitioning to the normal interstitial lattice and other trap sites was also analyzed, revealing that micropores are the major hydrogen trap site in the $\mathrm{Al}-\mathrm{Mg}$ alloy with low hydrogen content. It can be inferred that excess hydrogen in solid aluminum is predominantly partitioned to the micropores, and that occupancies of other trap sites are elevated with further increases in hydrogen concentration. It has been also clarified that the rate of trap site occupancies in dislocations and grain boundaries is very high, although the absolute amount of hydrogen trapped at grain boundaries is one to two orders of magnitude smaller than at the other trap sites.

\section{Acknowledgements}

The synchrotron radiation experiments were performed with the approval of JASRI through proposal numbers 2006A1056, 2007A1618 and 2007B1078. This work was undertaken as part of a Grant-in-Aid for Scientific Research (A) from the JSPS, as subject No. 20246102. The authors thank Dr. Katsumi Koyama for analyzing the hydrogen content of the materials used. One of the authors (HT) is also grateful for the support of the Light Metal Educational Foundation.

\section{References}

[1] Talbot DEJ. Inter Metall Rev 1975;20:166-184

[2] Itoh G, Kanno M. KINZOKU 1996;66:599-610 
[3] Talbot DEJ. The effects of hydrogen in aluminium and its alloys. Leeds: MANEY Publishing, 2004. p.178.

[4] Young GA Jr., Scully JR. Acta Mater 1998;46:6337-6349

[5] Scully JR, Young GA Jr., Smith SW. Mater Sci Forum 2000;331-337:1583-1600

[6] Smith SW, Scully JR. Metall Mater Trans A 2000;31A:179-193

[7] Russell AS. Met Progr 1949;55:827

[8] Outlaw RA, Peterson DT, Schmidt FA. Metall Mater Trans A 1981;12A:1809-1816

[9] Birnbaum HK, Buckley C, Zeides F, Sirois E, Rozenak P, Spooner S, Lin JS. J of Alloys and Compounds 1997;253-254:260-264

[10] Anyalebechi PN, Hogarth J. Metall Mater Trans B 1994;25B:111-122

[11] Ichimura M, Imamura M. J Japan Inst Met 1980;44:1045-1052

[12] Imanishi M, Fukumura T, Miyamoto S, Iwasaki M. J Appl Phys 1987;61:5485-5486

[13] Jordan MF, Denyer GD, Turner AN, Porosity J Ins Metals 1962;91:48.

[14] Kubaschewski O, Cibula A, Moore DC. Gases and metals. London: Iliffe books, 1970. p.32.

[15] Wang A, Thomson PF, Hodgson PD, Mater J Proc Tech 1996;60:95

[16] Toda H, Minami K, Kobayashi M, Koyama K, Ichitani K, Suzuki Y, Uesugi K. Acta Mater under review.

[17] Toda H, Hidaka T, Kobayashi M, Kobayashi T, Uesugi K, Suzuki Y. Proc 10th Asian Foundry Congress 2008;:121-127

[18] Chaijaruwanich A, Lee PD, Dashwood RJ, Youssef YM, Nagaumi H. Acta Mater 2007;55:285293

[19] Toda H, Sinclair I,Buffière JY, Maire E, Khor KH, Gregson P, Kobayashi T. Acta Mater 2004;52:1305-1317

[20] Qian L, Toda H, Uesugi K, Kobayashi T, Ohgaki T, Kobayashi M. Appl Phys Lett 2005;87:241907. 
[21] Toda H, Ohgaki T, Uesugi K, Kobayashi M, Kuroda N, Kobayashi T, Niinomi M, Akahori T, Makii K, Aruga Y. Metall Mater Trans A 2006;37A:1211-1220

[22] Kobayashi M, Toda H, Kawai Y, Ohgaki T, Uesugi K, Wilkinson DS, Kobayashi T, Aoki Y, Nakazawa M. Acta Mater 2008;56:2167-2181

[23] Qian L, Toda H, Uesugi K, Kobayashi M, Kobayashi T. Phys Rev Lett 2008;100:115505

[24] Toda H, Uesugi K, Takeuchi A, Minami K, Kobayashi M, Kobayashi T. Appl. Phys. Lett. 2006; 89: 143112

[25] Horikawa K, Kuramoto S, Kanno M. Acta Mater 2001;49:3981-3989

[26] Keh AS, Weissmann S. Electron Microscopy and Strength of Crystals. In: Thomas G, Washburn J, editors. New York(NY): Interscience Publishers, 1963. p.231-299.

[27] Cloetens P, Pateyron-Salome M, Buffière JY, et al. J Appl Phys 1997;1:5878

[28] Uesugi K, Takeuchi A, Suzuki Y, SPIE Proceedings 2006;6318:63181F

[29] W. E. Lorensen and H. E. Cline. Computer graphics (ACM) 1987; 21: 163-169.

[30] Cloetens P, Pateyron-Salome M, Buffière JY, Peix Baruchel G.J, Peyrin F, Schlenker M. J Appl Phys 1997;81:5878

[31] Urano Y, Noguchi F, Miura H, Chem J. Software 1996;3:91

[32] Goodhew PJ, Tyler SK. Proc R Soc Lond 1981;A377:151-184

[33] Raven C, Snigirev AA, Koch A, Snigireva I, Kohn V. Proc. SPIE Phase Contrast II, $1997 ; 3149: 140$

[34] Talbot DEJ, Granger DA. J Inst Metals 1963-64;92:290-297

[35] Rothaut J, Schroeder H, Ullmaier H. Philos Mag A 1987;47:781-795

[36] Nichols FA. J Nucl Mater 1969;30:143

[37] Greenwood GW, Boltax A. J Nuclear Mater 1962;5:234-240

[38] Markworth AJ. Metall Trans 1973;4:2651

[39] Kobayashi M, Toda H, Minami K, Mori T, Uesugi K, Takeuchi A, Suzuki Y. J Japan Inst Light 
Met 2008;: in press.

[40] Trinkaus H. Raddiation Effects 1983;78:189-211

[41] Watson JW, Meshii M. Aluminum Alloys. In Vasudevan AK, Doheuty RD, editors. Boston (MA): Academic Press, 1989. p.501-521.

[42] Baba Y. Proc ICSMA, Supplement to Trans JIM 9 1968;: 356

[43] Smith SW, Scully JR. Metall Trans A 2000;31A:179-193

[44] Leger M, Piercy GR. Philos Mag A 1981;43:377-385

[45] Oriani RA. Acta Metall 1970;18:147

[46] Ellerbrock HG, Vibrans G, Stuwe HP. Acta Metall 1972;20:53

[47] O’Dette JH. J Of Met 1957;9:924

[48] Tanguy D, Magnin Th. Colloque Advances in Mechanical Behaviour, Plasticity and Damage.In Miannay D,editor. Proceedings of EUROMAT 2000, vol. 2. New York (NY); Elsevier, 2000. p.1213-1218.

[49] Edwards R, von Eichenauer W. Proc Royal Soc 1962;270A:90-102

[50] Saito H, Iijima Y, Hirano K. J Japan Inst Light Met 1986;36:286-291

[51] Ogo H, Toda H, Kobayashi M, Uesugi K, Suzuki Y. Mater. Trans. 2009, under review. 
Caption list

Fig. 1 Explanation for detecting micropores heterogeneously nucleated on intermetallic compound particles. Each pore is expanded one to thirteen voxels in 3D. (a) 2-D tomographic slice of a reconstructed volume, (b) segmented pores and particles and (c) pore image after the expansion. Here, pore $\mathrm{C}$ is identified to be isolated, and pores $\mathrm{A}$ and $\mathrm{B}$ are identified to nucleate on particles $\mathrm{P} 1 \sim \mathrm{P} 3$.

Fig. 2 3-D perspective views of micropores in alloy $\mathrm{HH}$ in various heat-treatment conditions. Note that only micropores were extracted and shown here. 
Fig. 3 3-D perspective views of micropores in alloy MH in two heat-treatment conditions. Note that only micropores were extracted and shown here.

Fig. 4 3-D perspective views of micropores in alloy LH in two heat-treatment conditions. Note that only micropores were extracted and shown here.

Fig. 5 3-D perspective views of micro-pores in 5N-Al in two heat-treatment conditions. Note that only micropores were extracted and shown here.

Fig. 6 Enlarged 3-D perspective views of micropores in alloy $\mathrm{MH}$ and 5N-Al in various heattreatment conditions. Note that only micropores were extracted and shown here.

Fig. 73 -D perspective view of micropores in alloy $\mathrm{HH}$ observed after being exposed at $703 \mathrm{~K}$ for $18 \mathrm{~h}$. The imaging-type microtomography set-up was used to obtain this ultra-high resolution image. Note that submicrometer micro-pore is not seen in the region.

Fig. 8 Variations in average diameter of micropores in alloys $\mathrm{LH}, \mathrm{MH}, \mathrm{HH}$ and $5 \mathrm{~N}-\mathrm{Al}$ during exposure at $823 \mathrm{~K}$.

Fig. 9 Size distributions of micropores in alloys (a) LH, (b) $\mathrm{MH}$, (c) $\mathrm{HH}$ and (d) 5N-Al in various heat-treatment conditions.

Fig. 10 Variations in volume fraction of micropores in alloys $\mathrm{LH}, \mathrm{MH}, \mathrm{HH}$ and $5 \mathrm{~N}-\mathrm{Al}$ during exposure at $823 \mathrm{~K}$.

Fig. 11 Ratio of micropores heterogeneously nucleated on particles. The extent of dilation is varied 
to see the effects of the Fresnel diffraction.

Table 1 Average size and number density of micropores together with total hydrogen content.

Table 2 Size ratio $d \max / d$ in alloys $\mathrm{LH}, \mathrm{MH}$ and $\mathrm{HH}$ in various heat-treatment conditions.

Table 3 Measured hydrogen content together with the estimated content of hydrogen trapped within micropores.

Table 4 Microstructural parameters for hydrogen trapping sites; micropores, grain boundary and dislocation.Table 5 Estimated trap site coverage and the amount of hydrogen at each trap site. 

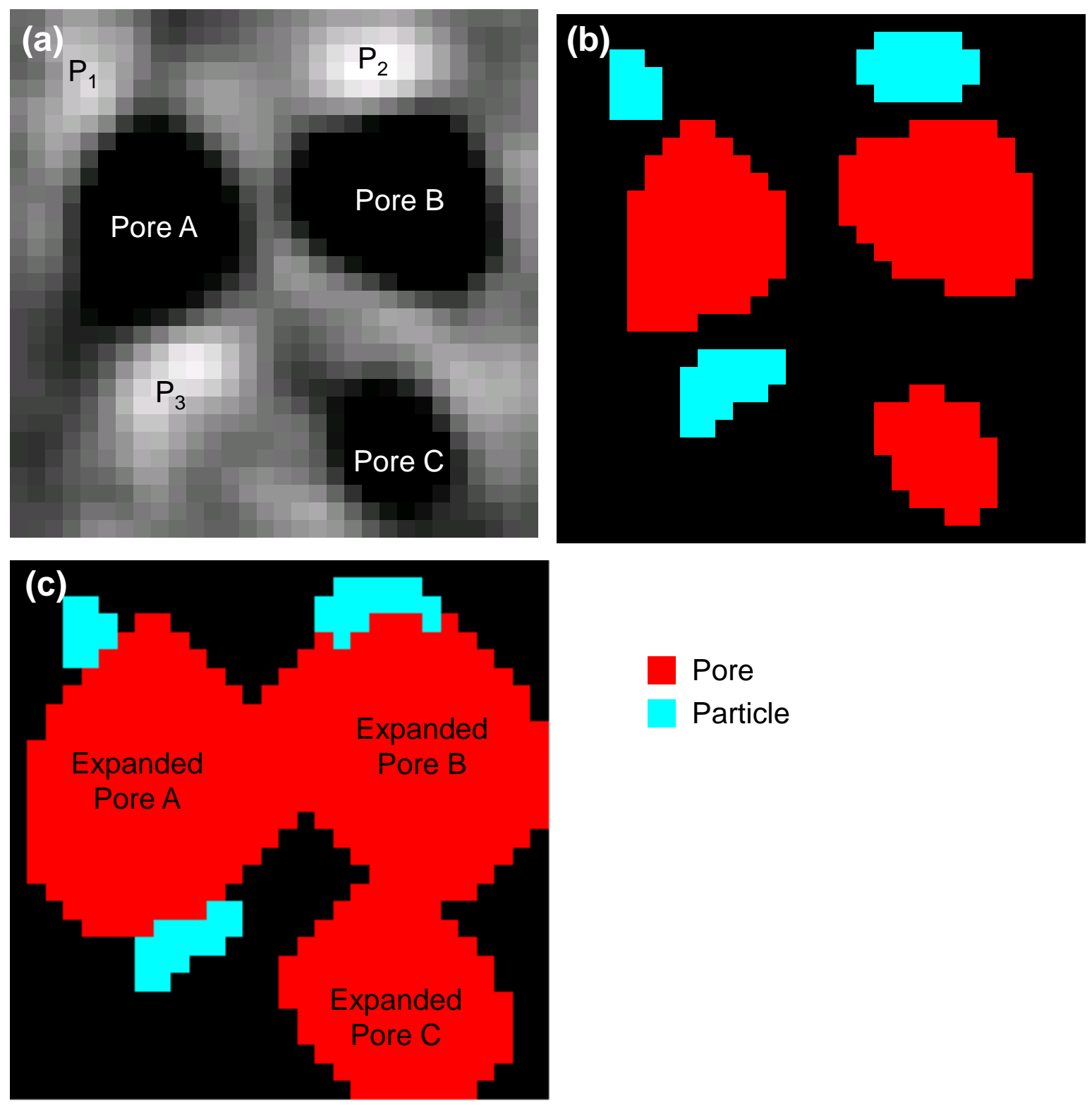

Fig. 1 Explanation for detecting micropores heterogeneously nucleated on intermetallic compound particles. Each pore is expanded one to thirteen voxels in 3D. (a) 2-D tomographic slice of a reconstructed volume, (b) segmented pores and particles and (c) pore image after the expansion. Here, pore $C$ is identified to be isolated, and pores $A$ and $B$ are identified to nucleate on particles $P_{1} \sim P_{3}$. 


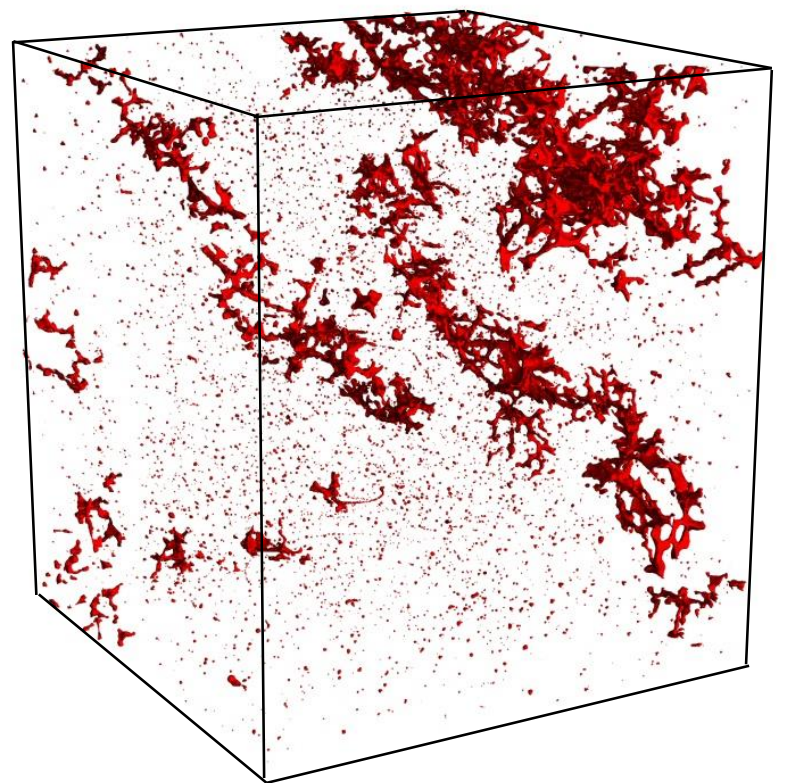

(a) As-cast

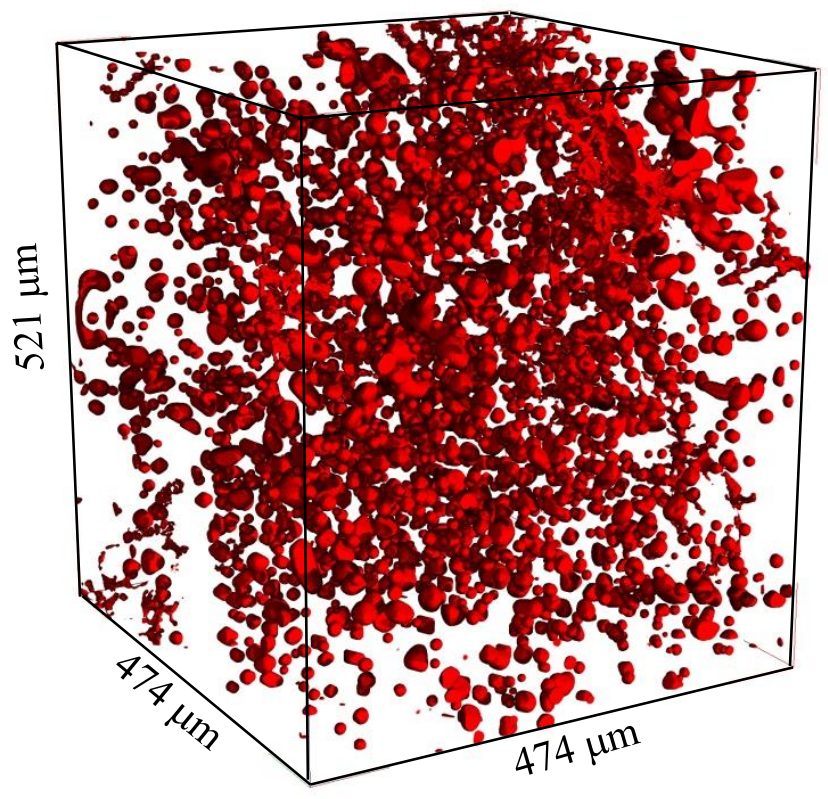

(c) $823 \mathrm{~K}-90 \mathrm{~h}$ after (b)

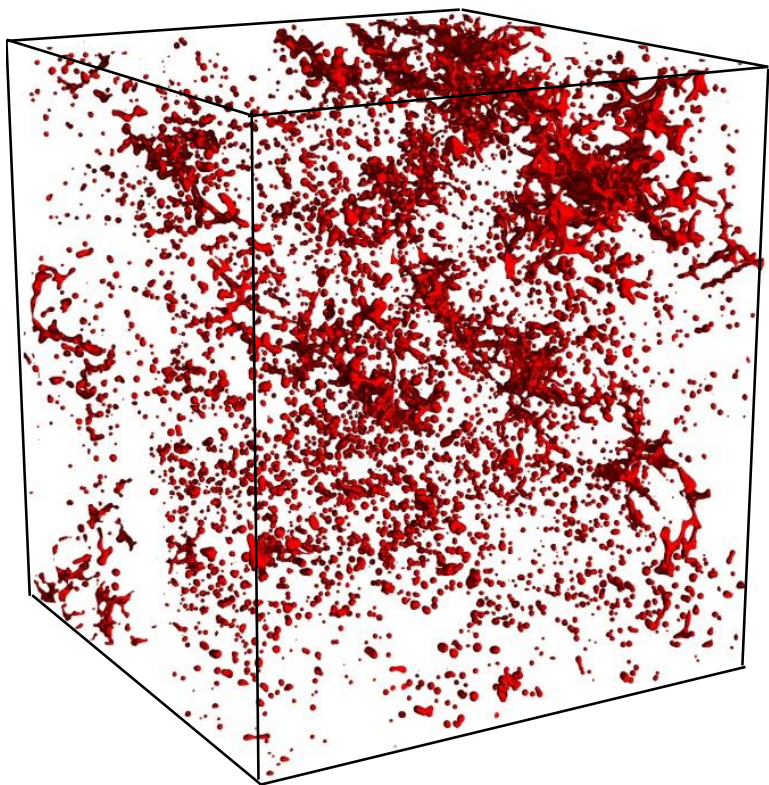

(b) After homogenization at $703 \mathrm{~K}$ for $18 \mathrm{~h}$ 


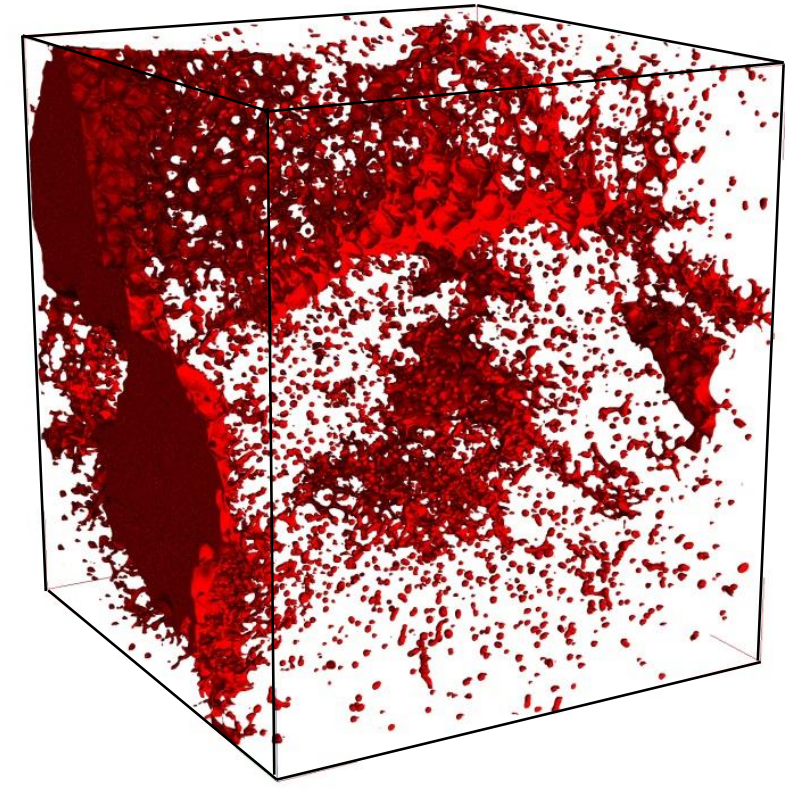

(a) After homogenization at $703 \mathrm{~K}$ for $18 \mathrm{~h}$

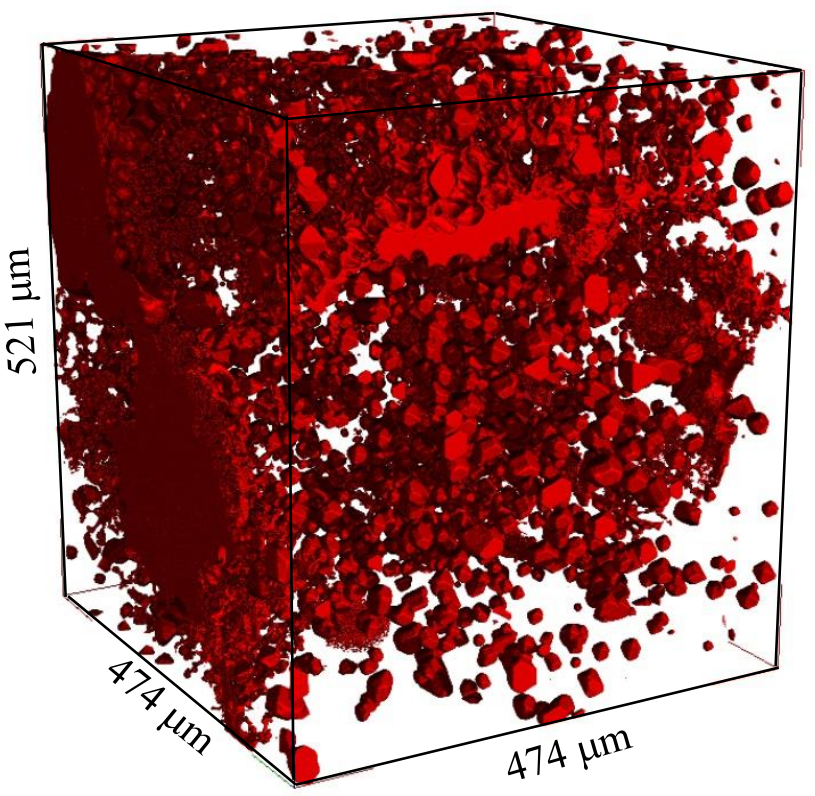

(b) $823 \mathrm{~K}-90 \mathrm{~h}$ after (a)

Fig. 3 3-D perspective views of micropores in alloy $\mathrm{MH}$ in two heat-treatment conditions. Note that only micropores were extracted and shown here. 


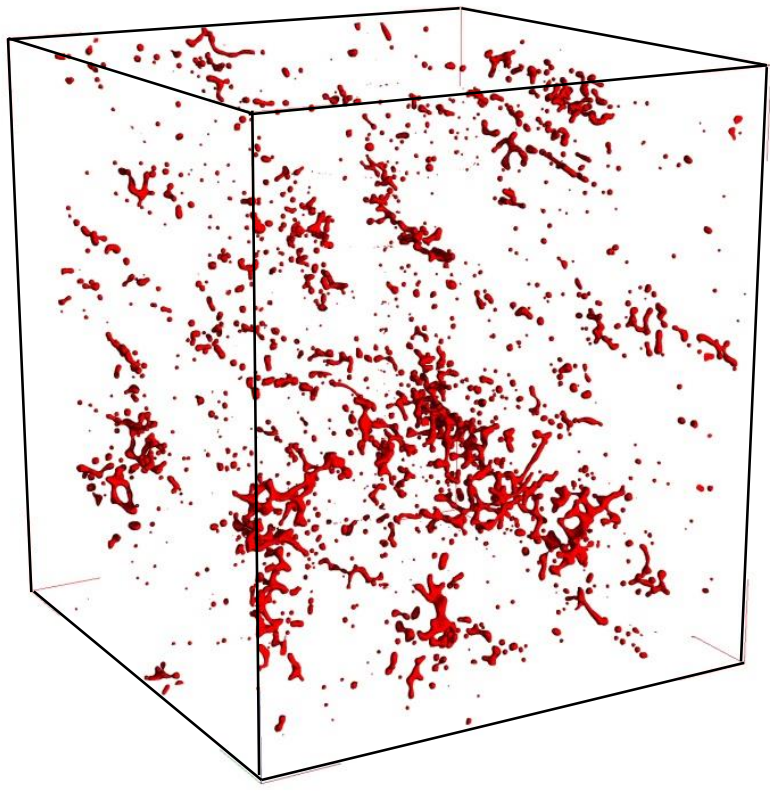

(a) After homogenization at $703 \mathrm{~K}$ for $18 \mathrm{~h}$

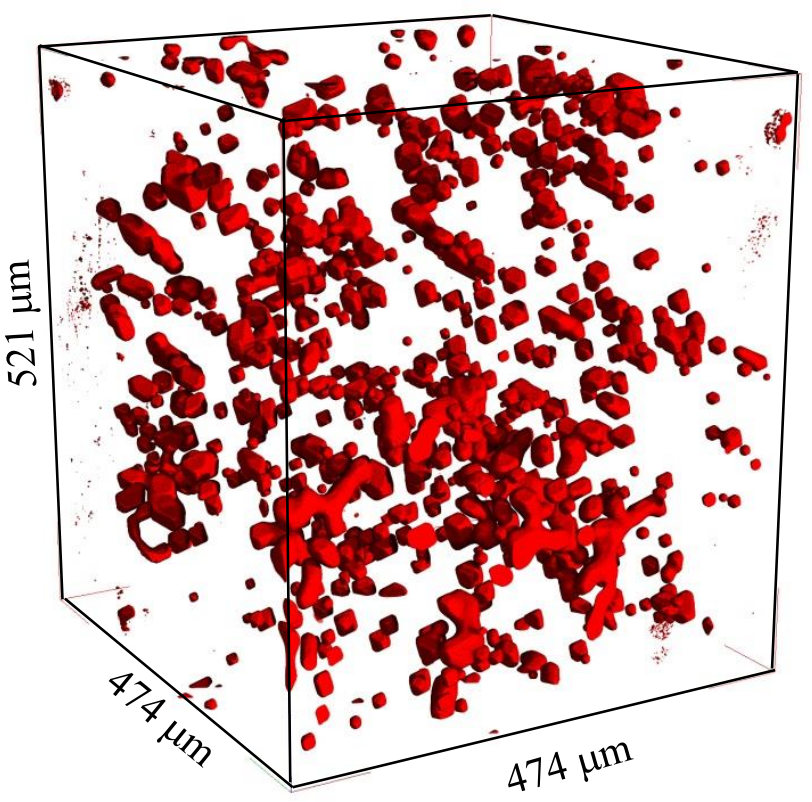

(b) $823 \mathrm{~K}-90 \mathrm{~h}$ after (a)

Fig. 4 3-D perspective views of micropores in alloy LH in two heat-treatment conditions. Note that only micropores were extracted and shown here. 


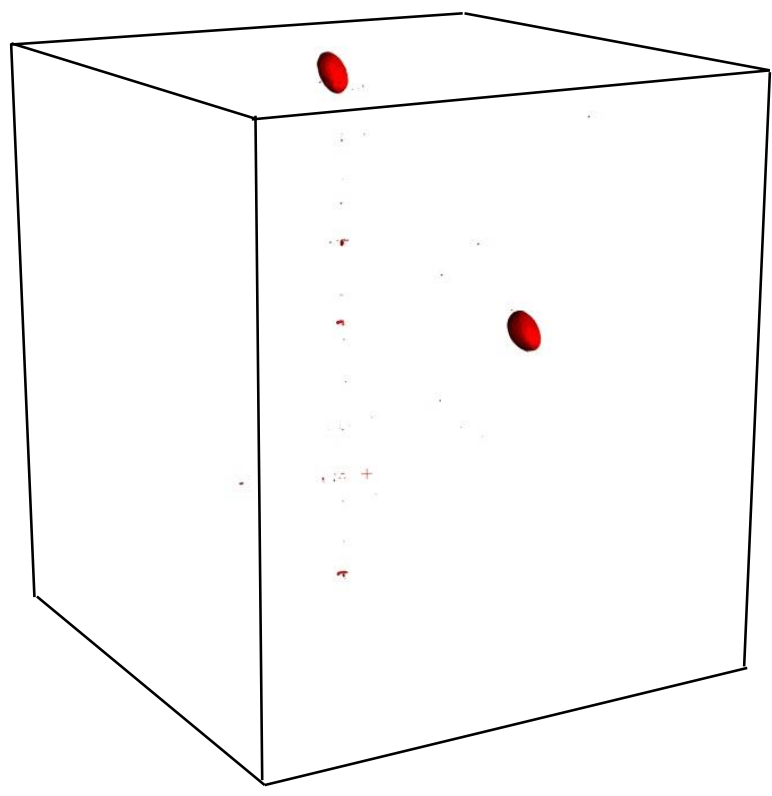

(a) As-cast

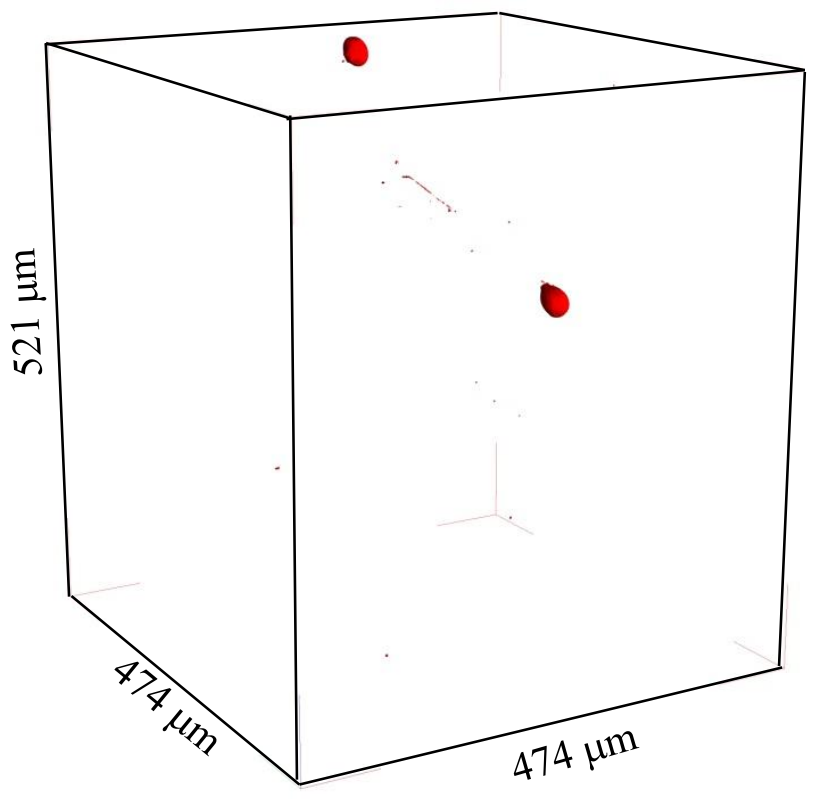

(b) $823 \mathrm{~K}-90 \mathrm{~h}$ after (a)

Fig. 5 3-D perspective views of micro-pores in $5 \mathrm{~N}-\mathrm{Al}$ in two heat-treatment conditions. Note that only micropores were extracted and shown here. 


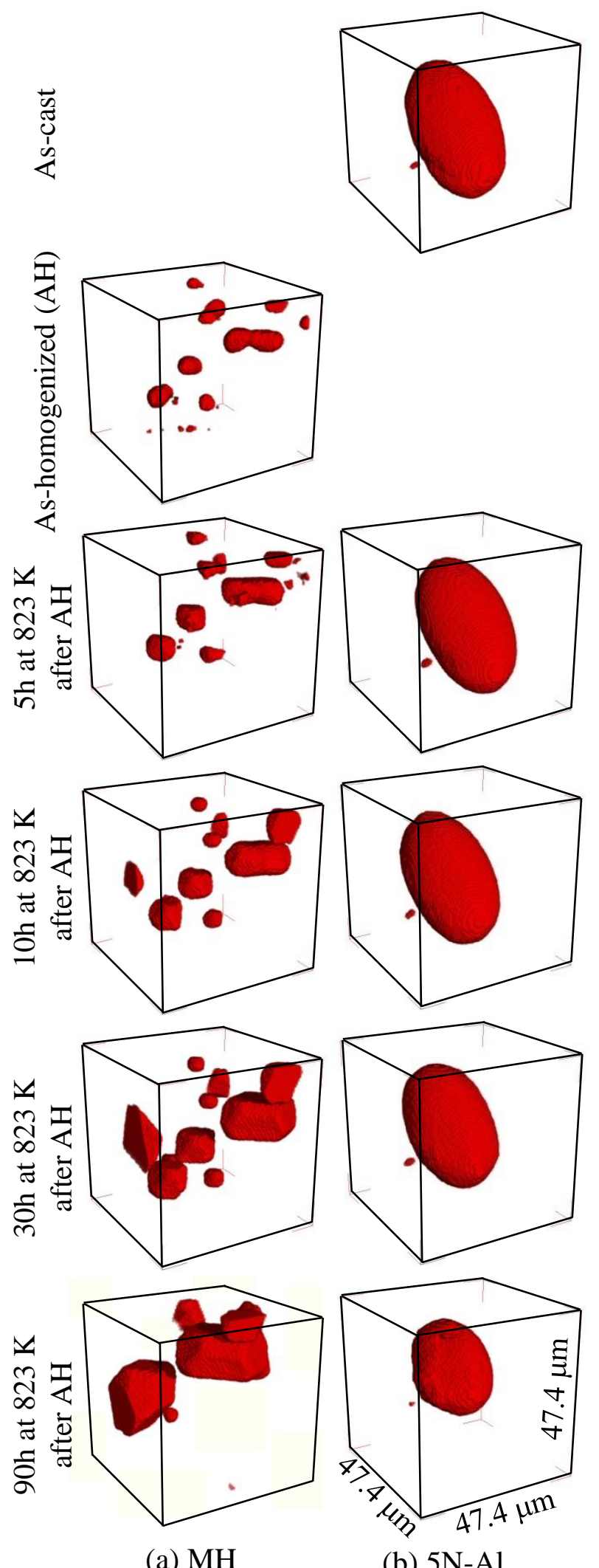

Fig. 6 Enlarged 3-D perspective views of micropores in alloy $\mathrm{MH}$ and $5 \mathrm{~N}-\mathrm{Al}$ in various heat-treatment conditions. Note that only micropores were extracted and shown here. 


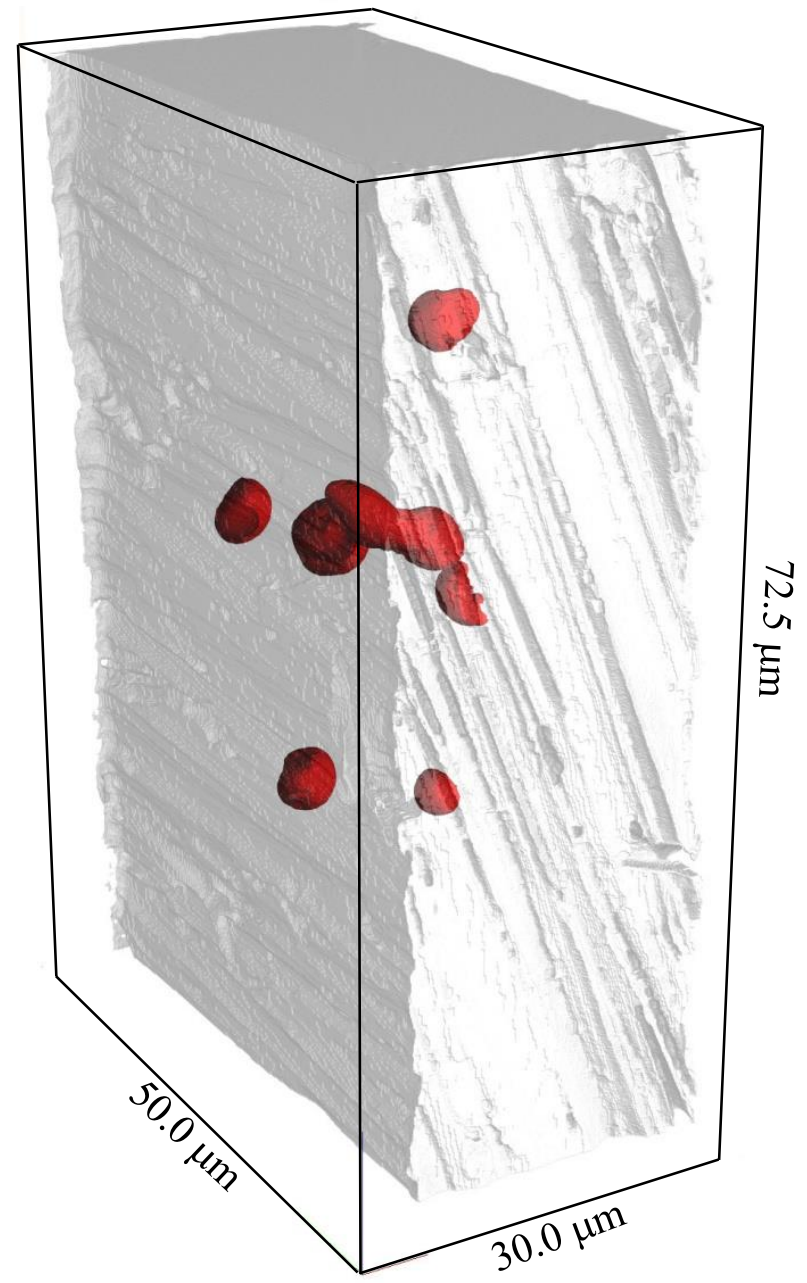

Fig. 73 -D perspective view of micropores in alloy $\mathrm{HH}$ observed after being exposed at $703 \mathrm{~K}$ for $18 \mathrm{~h}$. The imaging-type microtomography set-up was used to obtain this ultra-high resolution image. Note that submicrometer micro-pore is not seen in the region. 


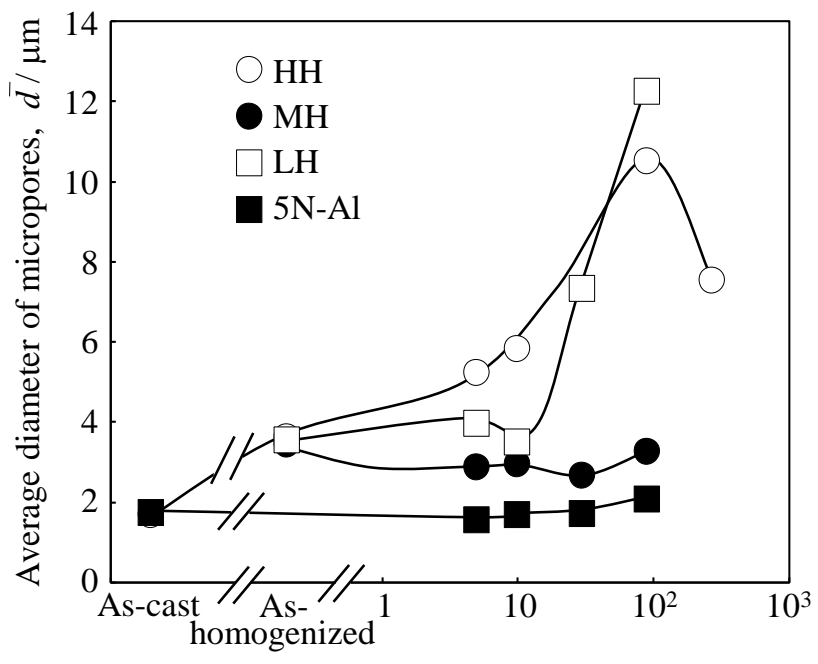

Holding time at $823 \mathrm{~K}, t / \mathrm{h}$

Fig. 8 Variations in average diameter of micropores in alloys $\mathrm{LH}, \mathrm{MH}, \mathrm{HH}$ and $5 \mathrm{~N}-\mathrm{Al}$ during exposure at $823 \mathrm{~K}$. 


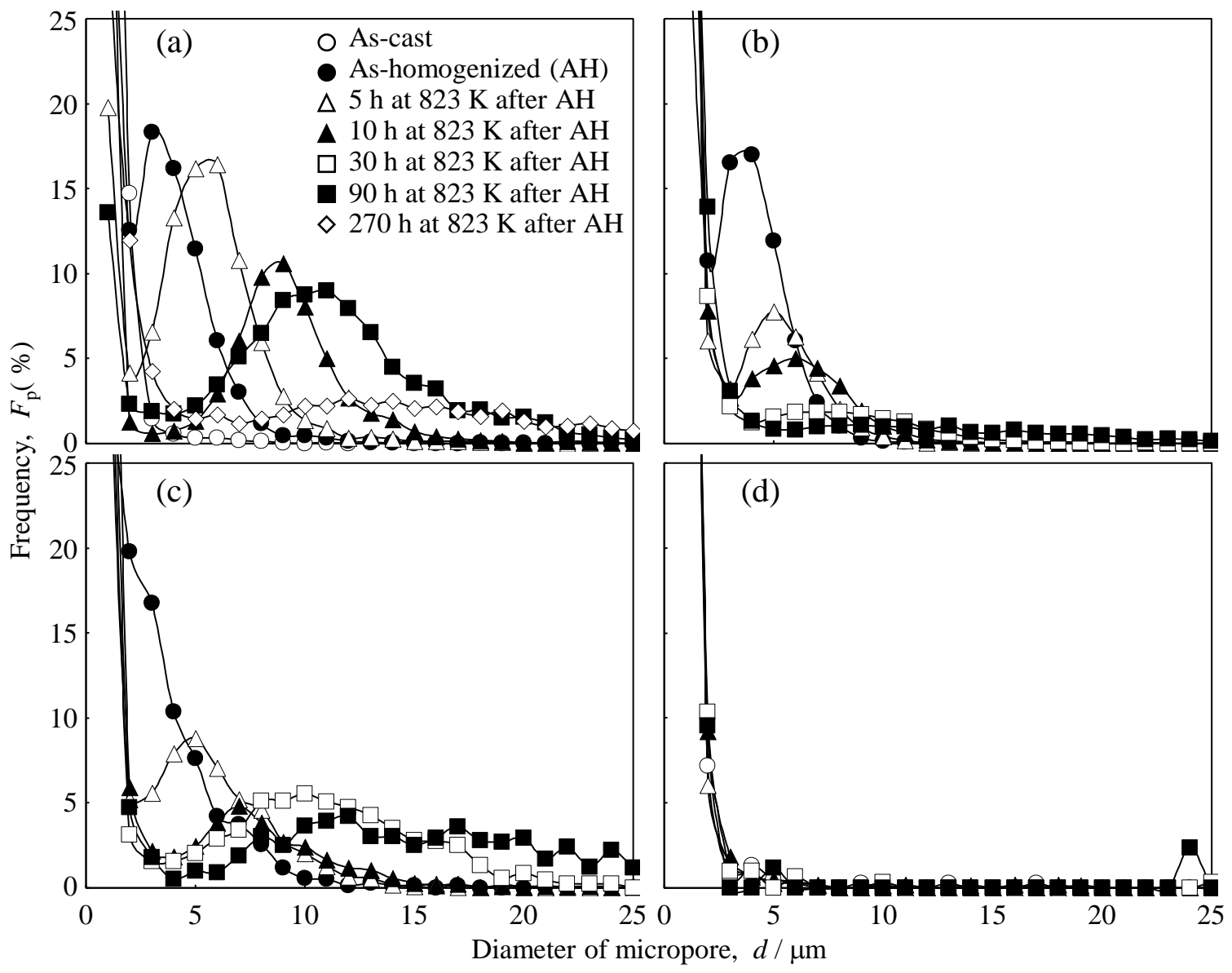

Fig. 9 Size distributions of micropores in alloys (a) $\mathrm{LH}$, (b) $\mathrm{MH}$, (c) $\mathrm{HH}$ and (d) $5 \mathrm{~N}-\mathrm{Al}$ in various heat-treatment conditions. 


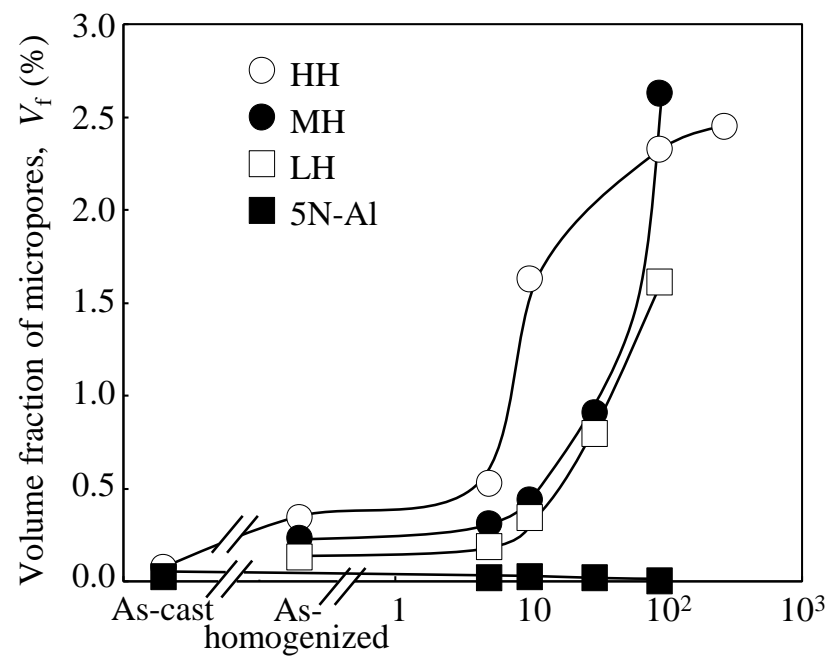

Holding time at $823 \mathrm{~K}, t / \mathrm{h}$

Fig. 10 Variations in volume fraction of micropores in alloys $\mathrm{LH}, \mathrm{MH}, \mathrm{HH}$ and $5 \mathrm{~N}-\mathrm{Al}$ during exposure at $823 \mathrm{~K}$. 


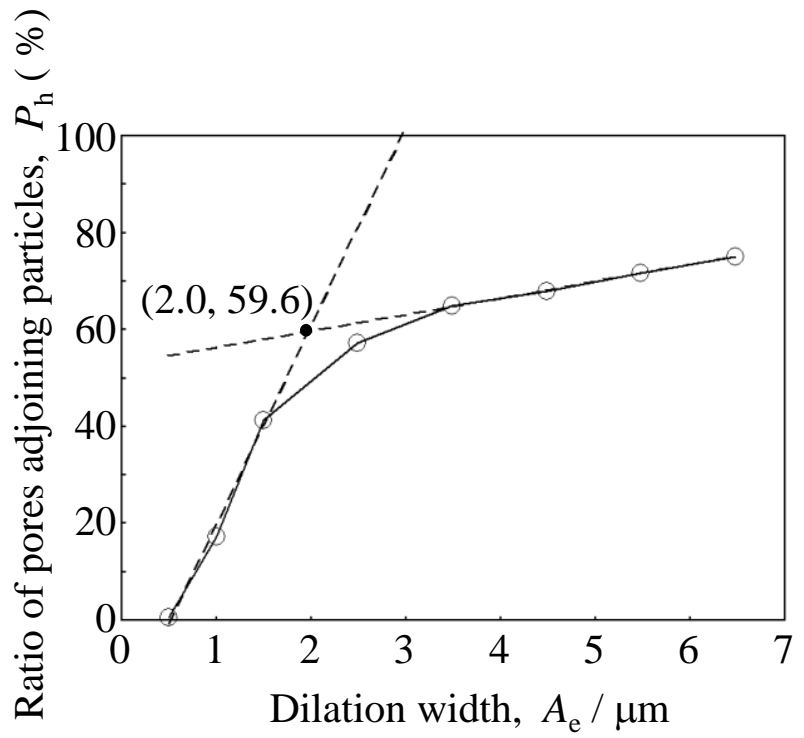

Fig. 11 Ratio of micropores heterogeneously nucleated on particles. The extent of dilation is varied to see the effects of the Fresnel diffraction. 
Table 1 Average size and number density of micropores together with total hydrogen content.

\begin{tabular}{cccc}
\hline \hline & $\begin{array}{c}\text { Average diameter of } \\
\text { micropores, } \bar{d} / \mu \mathrm{m}\end{array}$ & $\begin{array}{c}\text { Number density of } \\
\text { micropores, } \rho_{\mathrm{p}} / \times 10^{12} \mathrm{~m}^{-3}\end{array}$ & $\begin{array}{c}\text { Total H content, } \\
M_{\mathrm{H}} / \mathrm{ml} / 100 \mathrm{gAl}\end{array}$ \\
\hline HH (As-homogeneized) & 3.6 & 54.7 & 5.12 \\
\hline MH (As-homogeneized) & 3.5 & 50.7 & 4.94 \\
\hline LH (As-homogeneized) & 3.6 & 16.1 & 0.30 \\
\hline
\end{tabular}


Table 2 Size ratio $d_{\max } / \bar{d}$ in alloys $\mathrm{LH}, \mathrm{MH}$ and $\mathrm{HH}$ in various heat-treatment conditions.

\begin{tabular}{lccc}
\hline \hline & HH & MH & LH \\
\hline As-cast & 1.9 & - & - \\
\hline As-homogeneized $(\mathrm{AH})$ & 2.2 & 2.2 & 2.3 \\
\hline 5 h at $823 \mathrm{~K}$ after AH & 2.0 & 2.9 & 2.6 \\
\hline 10 h at $823 \mathrm{~K}$ after AH & 2.5 & 3.2 & 3.3 \\
\hline
\end{tabular}


Table 3 Measured hydrogen content together with the estimated content of hydrogen trapped within micropores.

$(\mathrm{ml} / 100 \mathrm{gAl})$

\begin{tabular}{llcc}
\hline \hline & & $\mathrm{H}_{2}$ in micropores, $M_{\mathrm{H}}$ pore & Total $\mathrm{H}$ content, $M_{\mathrm{H}}$ \\
\hline \multirow{3}{*}{$\mathrm{Al}-5 \% \mathrm{Mg}$} & HH As-cast & 0.13 & 5.12 \\
\cline { 2 - 4 } & MH As-homogenized & 0.45 & 4.94 \\
\cline { 2 - 4 } & LH As-homogenized & 0.16 & 0.30 \\
\hline $5 \mathrm{~N}-\mathrm{Al}$ & As-cast & 0.02 & 0.29 \\
\hline
\end{tabular}


Table 4 Microstructural parameters for hydrogen trapping sites; micropores, grain boundary and dislocation.

\begin{tabular}{|c|c|c|c|c|}
\hline & & $\begin{array}{l}\text { Volume fraction of } \\
\text { micropores, } V_{\mathrm{f}}(\%)\end{array}$ & Grain size, $\mu \mathrm{m}$ & $\begin{array}{l}\text { Dislocation den- } \\
\text { sity, } \times 10^{13} \mathrm{~m}^{-2}\end{array}$ \\
\hline \multirow{3}{*}{$\mathrm{Al}-5 \mathrm{Mg}$} & HH As-cast & 0.071 & 205.8 & 10.88 \\
\hline & MH As-homogenized & 0.229 & 360.4 & 4.01 \\
\hline & LH As-homogenized & 0.150 & 469.6 & 2.85 \\
\hline $5 \mathrm{~N}-\mathrm{Al}$ & As-cast & 0.024 & - & 3.58 \\
\hline
\end{tabular}


Table 5 Estimated trap site coverage and the amount of hydrogen at each trap site.

\begin{tabular}{|c|c|c|c|c|}
\hline Materials & Trap sites & $\begin{array}{l}\text { Trap density, } N_{\mathrm{T}} / \\
\times 10^{6} \text { sites } / \mathrm{m}^{3}\end{array}$ & $\begin{array}{c}\text { Trapp site } \\
\text { occupancy, } \theta_{\mathrm{T}}\end{array}$ & $\begin{array}{c}\text { Trapped hydrogen, } \\
\times 10^{6} C_{T} / \text { atoms } \mathrm{H} / \mathrm{m}^{3}\end{array}$ \\
\hline \multirow{5}{*}{$\begin{array}{c}\mathrm{HH} \\
\text { As-cast }\end{array}$} & Interstitial & $5.85 \times 10^{22}=N_{\mathrm{L}}$ & $8.88 \times 10^{-5}=\theta_{\mathrm{L}}$ & $5.20 \times 10^{18}$ \\
\hline & Solute $\mathrm{Mg}$ atom & $1.23 \times 10^{21}$ & $9.21 \times 10^{-4}$ & $1.33 \times 10^{18}$ \\
\hline & Dislocation & $6.89 \times 10^{17}$ & 0.970 & $6.68 \times 10^{17}$ \\
\hline & Grain boundary & $8.47 \times 10^{16}$ & 0.992 & $8.40 \times 10^{16}$ \\
\hline & Micropore & - & - & $1.88 \times 10^{17}$ \\
\hline \multirow{5}{*}{$\begin{array}{c}\text { MH } \\
\text { As-homogenized }\end{array}$} & Interstitial & $5.85 \times 10^{22}=N_{\mathrm{L}}$ & $8.46 \times 10^{-5}=\theta_{\mathrm{L}}$ & $4.95 \times 10^{18}$ \\
\hline & Solute $\mathrm{Mg}$ atom & $1.23 \times 10^{21}$ & $8.78 \times 10^{-4}$ & $1.08 \times 10^{18}$ \\
\hline & Dislocation & $2.54 \times 10^{17}$ & 0.968 & $2.46 \times 10^{17}$ \\
\hline & Grain boundary & $4.84 \times 10^{16}$ & 0.991 & $4.80 \times 10^{16}$ \\
\hline & Micropore & - & - & $6.34 \times 10^{17}$ \\
\hline \multirow{5}{*}{$\begin{array}{c}\text { LH } \\
\text { As-homogenized }\end{array}$} & Interstitial & $5.85 \times 10^{22}=N_{\mathrm{L}}$ & $1.55 \times 10^{-6}=\theta_{\mathrm{L}}$ & $9.07 \times 10^{16}$ \\
\hline & Solute $\mathrm{Mg}$ atom & $1.23 \times 10^{21}$ & $1.61 \times 10^{-5}$ & $1.98 \times 10^{16}$ \\
\hline & Dislocation & $1.80 \times 10^{17}$ & 0.357 & $6.43 \times 10^{16}$ \\
\hline & Grain boundary & $3.71 \times 10^{16}$ & 0.677 & $2.51 \times 10^{16}$ \\
\hline & Micropore & - & - & $2.23 \times 10^{17}$ \\
\hline \multirow[b]{2}{*}{$5 \mathrm{~N}-\mathrm{Al}$} & Interstitial & $6.03 \times 10^{22}=N_{\mathrm{L}}$ & $4.09 \times 10^{-6}=\theta_{\mathrm{L}}$ & $2.46 \times 10^{17}$ \\
\hline & Dislocation & $2.26 \times 10^{17}$ & 0.594 & $1.34 \times 10^{17}$ \\
\hline \multirow[t]{2}{*}{ As-cast } & Grain boundary & - & - & - \\
\hline & Micropore & - & - & $3.40 \times 10^{16}$ \\
\hline
\end{tabular}

